Romantic relationships at work: Why love can hurt

Summary

The academic community, practitioner literature and newspapers have all taken an interest in workplace romance. This paper aims to review the literature on workplace romance and to argue that the issue of power is key to understanding the negative consequences for individuals and organizations, linking workplace romance with theories or explanatory models of power.

The paper first examines definitions of workplace romance, presents evidence of its preval ence, distinguishes between different types of workplace romance, and then looks at the main issues managers and organizations face when considering the issue. The approaches taken by research in management, law, psychology and sociology are contrasted. The motivations for romance and the place of culture are described. Secrecy, gender differences and the negative and positive outcomes for men and women are discussed. The link between romance and harassment is explored. The paper looks at what organizations have done to manage romance. The research methods that have been used are reviewed as are the gaps and weaknesses in order to make recommendations for future research. The review synthesizes accumulated knowledge in both research and practice, ending by identifying recommendations for managers. 
Romantic relationships at work: Why love can hurt

Introduction

Since the late 1970s workplace romance has been researched and debated by scholars and academics. It is likely that the first definition of workplace romance was 'a relationship between two members of the same organization that is perceived by a third party to be characterized by sexual attraction' (Q uinn 1977:30). M ore recently workplace romances have been defined by Pierce and A guinis (2001:206) as ' mutually desired relationships involving sexual attraction between two employees of the same organization'. Sexual attraction is thus a defining feature of workplace romance.

Surveys over the last few decades have clearly illustrated the prevalence of workplace romance. In the UK more than 70 per cent of employees have experienced a workplace romance (Clarke 2006). It is thought that up to a fifth of us meet our partners at work and a quarter to half of office romances lead to marriage (Furnham 2012). In the US a 2011 survey by $\mathrm{CareerB}$ uilder.com showed that 40 per cent of respondents had dated a coworker, while a third said they had married the person they dated at work (A dams 2011 2012; see also SHRM 2011). Crail (2006) reported that 71 per cent of survey respondents were aware of a romance currently happening in their office. N early a quarter of managers said they had been involved in a workplace romance at least once during their career (Peak 1995). W orkplaces are now seen as having an important sexual component ( $K$ akabadse and K akabadse 2004; Fleming 2007). Social-sexual behaviour is common in organizations, with a majority reporting that they experience it (Burke and M CK een 
1992). K akabadse and Kakabadse (2004) found that 60 per cent of their survey of 221 participants of different nationalities admitted to an intimate experience in the workplace.

The literature fails to draw out the different kinds of romance, but there are two essential factors: whether both parties are 'single', and whether there is an issue of consent. A workplace romance betw een single workers may be simply a 'one night stand' or the beginning or continuation of an established partnership. On the other hand, workplace romance relationships where one or both partners are involved in an existing relationship may potentially bring about the infamy of extra-marital affairs. A romance in which consent is in question may or may not result in accusations of harassment. These distinctions apply across relationships of same-gender or different-gender couples.

Only two types of workplace romance are identified in the literature: lateral and hierarchical (for example by K arl and Sutton 2000, and Pierce and A guinis 1997). A lateral romance is a relationship between employees of equal status. A hierarchical romance is one where the two employees are at different organizational levels, as when a manager is romantically involved with his or her subordinate. Hierarchical workplace romances are both more frequent and more problematic than lateral romances, involve power differences between those in the partnership, and are often a source of hostility (Powell 2001).

Romantic behaviour is frequently contrasted with sexually harassing behaviour, which is unwelcome, non-consensual, and a form of sex discrimination. For example Pierce et al. (1996) refer to workplace romance as a consensual relationship between two partners of opposite sex that does not constitute unwanted or harassing activity. Definitions also tend 
to assume that the romance is between two partners of the opposite sex (e.g. Dillard and Witteman 1985; M ainiero 1986; Powell and M ainiero 1990; Powell 1993; Pierce et al. 1996). The workplace romance literature has been fairly silent on the topic of same-sex romances (Powell and Foley 1998). While Rumens (2008) discusses gay men's friendships at work and Bowring and B rewis (2009) look at how a group of lesbian and gay employees manage their identities at work, neither examine workplace romance. The definitions also tend to exclude cross-organizational romances.

W orkplace romance presents a number of questions. One of the most important is: should workplace romance be banned because it can potentially hurt the organization and the couple? The research literature on workplace romance has been driven by a concern about potential negative impacts of workplace romance, in particular impacts on productivity and claims of favouritism or sexual harassment. The literature offers advice to managers on questions such as whether managers should treat romantic relationships as private affairs, external to the organization and its business, or should intervene with an anti-fraternization policy. This question has been debated since 1978 when M argaret M ead, an anthropologist, stated her opinion: 'Y ou don't make passes or sleep with people you work with' (1978). People who believe that expressions of sexuality should never appear at work get upset and expect management to do something (Powell and Foley 1998). 'Sexuality' and 'work' are seen as 'somehow at odds with each other' (Hearn and Parkin 1987:7). Blending the boundaries of personal and work life is considered a 'risky business' (B urke 2010), as it raises conflicts between professional codes of conduct and the right to privacy (M ainiero and J ones 2013). Consensual workplace romance can lead to negative outcomes such as job loss, litigation or negative publicity in newspapers 
(Williams et al. 1999). M cD onald (2000) illustrates the dangers managers face by entitling his article 'Failed workplace romances: If you' re lucky you'll just get sued'. The issue of workplace romance becomes highly topical when well-known individuals lose their jobs or professional reputations. Cases that have been widely discussed in the media include Clinton-Lewinsky (Powell 2000), in which consensual sexual relations between a married man and a single intern resulted in the impeachment of the US president, and the case of a then-married $M$ ary Cunningham who was accused of 'sleeping her way to the top' at the Bendix Corporation (Harrison and Lee 1986; Swartz et al. 1987). The Red Cross fired its married president because of a personal relationship with a subordinate (CN N 2007); the World Bank president resigned following a conflict of interest from his relationship with an employee; Boeing's chief executive lost his job after an 'improper relationship' with a colleague (Isidore 2005); and more recently a CIA chief resigned after his extra-marital affair was uncovered (B BC N ews 2012).

The research literature in human resource management and law has been driven by concerns about the harmful outcomes of workplace romance; this perspective has led to their contribution being functionalist and prescriptive. However in sociology and organizational theory, the approach has been quite different. This literature first notes how the issue of sexual ity in organizations has been largely untouched (Hearn and Parkin 1987; B urrell and Hearn 1989), as organizations are portrayed as being about control, instrumental rationality and the suppression of emotion. This view is particularly evident in neoclassical ideals of management. The literature goes on to acknowledge the place of gender, sex, eroticism and sexuality in organizations (B rewis and Grey 1994; B rewis and Linstead 2000; Shilling and M ellor 2010). R ather than assume a Freudian perspective 
portraying sexuality as inherently disorderly and dangerous, these theorists argue that workplaces define and shape sexual desire. Groups will often negotiate and resist pressures toward conformity with social norms (W illiams et al. 1999). It is argued that a social constructionist perspective is required, one which acknowledges that sexuality is an historical construct (B urrell 1984), coupled with a nuanced view of workplace sexuality.

Other sociologists take the argument a step further, for example suggesting that sexuality should be encouraged at work as a way of exploiting labour power and productive potential (M arcuse 1968). G herardi (1994:600) argues that our first act on meeting someone is to 'ascribe a gender identity', while B rewis (2005:497) adds that attaching a label of heterosexual, homosexual or bisexual is 'as common a practice'. Re-eroticization theory suggests that the removal of all oppressive structures will allow the full emergence of eros, making organizations more passionate, human and exciting places (Burrell 1992; B rewis and Linstead 2000). While not specifically addressing workplace romance, sociology and organizational theory discusses sexuality in organizations and a range of practices 'from feelings to flirtations to sexual acts, accomplished willingly, unwillingly or forcibly by those involved' (B urrell and Hearn 1989:13), demonstrating how sexuality is infused in all aspects of organizational life and how organization pervades every aspect of our sexuality (H earn and Parkin 1987; B rewis and Linstead 2000). The discipline looks at how expressions of sexuality are sanctioned and used by management (A bbot and Tyler 1998; Fleming 2007). It also acknowledges sexuality's pivotal role in the imbalances of power between genders. The struggle for power lies at the core of love and sexuality; men continue to have the upper hand (IIlouz 2012). L ove is one of the main 
causes of the divide between men and women, for when in love, men and women continue to perform the deep divisions that characterize their respective identities. Gender identities and hierarchy are played out and reproduced in the experience of workplace romance. This literature tends to look beyond whether expressions of sexuality are good or bad. Sexual harassment may be understood as a sexualized abuse of power, or more positively sex can perhaps provide the basis for re-energized relationships between work colleagues (Pringle 1989; B urrell 1992). Gallop (1997) goes as far as arguing that banning amorous relationships may be shutting down the possibilities that make relationships productive.

Methods for this review

This review draws from research on workplace romance published in academic journals in the fields of management, law, psychology and sociology, as well as practitioner journals such as Personnel Today and business magazines such as F orbes. There is a large literature; by 2010 there were about 400 articles on the topic. The vast majority of these originated in the US: for every 10 articles originating there, there is just one from outside (Boyd 2010). For this review, ECSCO host was used as a bibliographic database and a search was done with keywords 'workplace romance' for the period 1972 to the present. This produced 662 articles, many of which were actually on sexual harassment but had 'workplace romance' in their keyword selection. Those articles not about workplace romance were removed, though the present review does consider the links between sexual harassment and romance as this is an issue raised in the workplace 
romance literature. A review was conducted of those approximately 120 articles left with a particular emphasis on key researchers in the field, those most cited by others.

W hile the definitions of workplace romance assume a sexual relationship, there are studies of non-sexual love relationships at work (e.g. Lobel et al. 1994). This review is about workplace romance where there is physical intimacy, and sexual attraction is assumed as this is how the concept is defined. It is these relationships that provoke the more intense reactions and have the greater consequences. It will not include relationships such as strong friendships and will not include romantic relationships between those who do not work, for example adolescents whose formative experiences of romance are studied by social psychologists, or the general population who respond to surveys about romance (for example questions about their perceived romantic competence) but may not be in work.

'Managing', power and romance

Although organizations have historically attempted to suppress, control and contain sexuality (Roy 1974; B urrell 1984) as sexuality and other 'personal forces' have been perceived to be at odds with productivity, inappropriate, 'out of place' in organizational life (Schultz 2003), management attempts to desexual ize the organization may have the opposite effect if subordinates' resistance leads them to engage in behaviour simply because it is forbidden (B urrell 1984). A ttraction at work usually happens between those who work together closely, collaborate, are similar in attitude to each other and find it easy to interact (Quinn 1977; Byrne and Neuman 1992; Salvaggio et al. 2011b). The increase in interaction as well as a sense of common purpose increases the likelihood of 
personal attraction. Sharing an experience, such as the same reaction to an event or a coworker, can also lead to interpersonal attraction (Pinel et al. 2006) and romance.

The difficulties of managing intimacy and attraction in working relationships are particularly evident in the mentor-protégé relationship: it has been estimated that 10 per cent of mentors and protégés become sexually intimate (Burke 2010), which raises issues about power. Similarly the prevalence of romance in universities presents managers with concerns about the abuse of power and conflicts of interest. However, sexual relationships between staff and students flourish (Reiss 2008). In US universities approximately 17 per cent of female graduate students said that they had a sexual relationship with at least one of their professors while at university (Pope et al. 1979; Glaser and Thorpe 1986), and 26 per cent of male faculty reported sexual relationships with female students (Fitzgerald et al. 1988). In the UK it was found that just 50 of 102 educational institutions had policies requiring staff to declare sexual or other relationships with students that might give rise to a conflict of interest. Of those who had a relationship, only 30 of 100 staff declared it to avoid conflict of interest (R eiss 2008).

In these research findings we have a clear illustration of Lukes's (1986) threedimensional model of power. In the one-dimensional view of power, person A has power over person B; this power comes from A's higher rank in the organization and their ability to utilize some reward such as higher marks or positive evaluations in return for sexual favours. The second dimension draws on B achrach and B aratz (1962) to acknowledge the ways in which decisions are prevented from being taken on issues over which there is an observable conflict of subjective interests, where there is a structural 
face of power lurking in the dark. A minority of relationships between staff and students are declared or taken into account. Policies on intimate relationships are ignored and the romantic relationships, with their inherent conflicts of interest, are rendered invisible. The failure to make decisions ensures that it is unlikely that the status quo will change. The third dimension incorporates the first two but also 'allows that power may operate to shape and modify desires and beliefs in a manner contrary to people's interests' (Lukes 1986:9). The existence of relations of dominance, in this case the powerful over the less powerful, prevents grievances and conflict for forming by shaping the perceptions and cognitions of subordinate groups so that romance is seen as harmless fun, natural and unchangeable.

This third dimension of power is illustrated again in the research (e.g. Powell and Foley 1998) that attempts to explain the prevalence of romance with three reasons. Firstly it notes how workplace romance has increased due to the influx of women into the workforce, 'upsetting traditional organizational behavior modes' (Swartz et al. 1987:22) and creating 'numerous new problems for the personnel management function' (Ford and M CL aughlin 1987:100), as if women are to blame (Riach and Wilson 2007). The increasing number of women in the workplace then leads to greater opportunity for individuals to form romantic relationships. Secondly, people work longer hours (W orrall and Cooper 2001) and so are spending more time at work and less time with family. Third, the tendency to marry later and the higher divorce rate is likely to result in a greater incidence of workplace romance (Dillard et al. 1994), although divorce may also be a consequence of workplace romance. R esearch has also looked at the motivation for romance. 
Motivation and the place of culture in romance

Research has identified a number of different motives for participation in a workplace romance. It may be a love motive - a sincere desire to seek a long-term companion; an ego motive - a desire to seek adventure, excitement, sexual experience or ego satisfaction; or a job-related motive - a desire to seek advancement, security, power, financial rewards, lighter workloads or increased holiday time (Quinn 1977; M ainiero 1986; Dillard and B roetzmann 1989; A nderson and Fisher 1991; Brown and Allgeier 1996). It is the ability to offer rewards such as advancement, security, power, financial benefit, lighter workloads or increased holiday time that gives the superior the opportunity to exercise their power and fulfil the employee's motive. Employees may have multiple motives for participation in the romance and a pair may have different motives. Culture too can influence motivation.

Contextual factors such as organizational cultures, types of jobs and patterns of work have been shown in research to impact on friendship at work (Cohen 1992; W ellman 1992), so it is likely that they will also impact on romance. Some professions provide fertile grounds for romantic and sexual relationships. M arketing and advertising score high, while architecture scores low (B urke 2010). Long work hours coupled with high work demands encourage individuals to spend increasing amounts of time at work (Pierce et al. 1996; Gautier 2007). Organizational culture acts as a signal to employees regarding what types of behaviour will be tolerated (Salvaggio et al. 2011b). Those that signal to workers that mutual attraction is acceptable are more likely to witness romance. There has been little attention given to the context in which workplace romances occur 
(Williams et al. 1999), but research has found that they are more likely to occur if the environment is characterized by both men and women being sexualized through flirting, joking and provocative dressing (Society for Industrial and Organizational Psychology 2013). The psychological and structural context of work, such as the norms for sexual behavior, are more relevant for understanding workplace romance than basic demographic characteristics of employees such as age or gender ratios (Salviaggio et al. 2011a). Research has also found that slow-paced, traditional and conservative organization cultures (for example, found in banking and finance) are associated with fewer workplace romances while fast-paced liberal cultures (as found in advertising) are associated with more. Romance is also more likely in 'hot' workplace climates: those characterized by a hedonistic orientation and a focus on physical attractiveness ( $M$ ano and Gabriel 2006), for example spa resorts. J obs that are characterized by a sexual simmer (Giuffre and Williams 1994) or a high level of sexual innuendo and flirtation offer a more hospitable climate for romance, for example restaurants (Salvaggio et al. 2011a). The psychological and structural context of work, for example the norms for sexual behaviour, are important to understanding the antecedents of workplace romance. A pplied psychologists have looked at workers' reactions to sexual advances and have demonstrated gender differences.

Gender differences and workplace romance

M en and women see sexual behaviours differently (Gutek 1985). M en tend to view the same sexual behaviours as less offensive and harmful than women (Berdahl 2007) and hold more favourable attitudes towards romance and sexual intimacy at work (Pierce 
1998). Some men report wanting to experience more social behaviour at work (Berdahl et al. 1996), probably because of gender differences in power.

Reactions may differ depending on who workers find attractive. In a study of restaurants, Giuffre and Williams (1994) found that waiters and waitresses engaged in flirtatious, sexual bantering with co-workers of the same race, ethnicity, class and sexual orientation. However they defined identical behaviours between co-workers of different backgrounds as sexual harassment. This suggests that it is the characteristics of the individual rather than the sexual behaviour that is objectionable.

W hile sexual behaviour at work is primarily between peers (Gutek 1985; US M erit Systems Protection Board 1994), individuals with more power who initiate sexual behaviour should be perceived as more threatening and coercive than those with equal or less power (B ourgeois and Perkins 2003). As men tend to have more power in organizations, sexual behaviour initiated by men should be more potentially threatening and coercive than that initiated by women (B erdahl and A quino 2009). In a study of sexual behaviour at work (e.g. sexual jokes and propositions), Berdahl and A quino (2009) found that some women and many men enjoyed that behaviour at work. Over onefourth found it fun or flattering, while almost half saw it as benign, but slightly more found it stressful or bothersome. $M$ en tended to enjoy ambient sexual behaviour (sexual jokes, language and materials) and particularly direct sexual behaviour (direct sexual comments and advances), but women tended to dislike both. Employees' work-related outcomes (withdrawing from work, neglecting tasks, considering quitting) were worse the more they experienced sexual behaviour in their workplaces, regardless of whether 
they disliked or enjoyed the behaviour. These results suggest that sexual behaviours at work cause harm. A study by Collins (1983) also showed that many of the women felt that sexual liaisons at work had been harmful to them. Sexual behaviours may not be considered 'romantic'. M uch social sexual behaviour is unclear and ambiguous (Sias 2008). For example, what one person may consider 'flirting' may be viewed by another as harassment. Flirting is 'risky' behaviour in that the target of the flirting may reject the overture and/or interpret the behaviour as harassment ( $Y$ elvington 1996). There is a very thin line between harassment and romantic behaviour, and it can be difficult to separate mutually consenting romances from sexual exploitation both empirically and philosophically (Fitzgerald et al. 1988).

There are reasons why women might be more cautious than men about being involved in a workplace romance. Women's and men's experiences in workplace romance are very different (Quinn 1977; Dillard and M iller 1988; Powell and Foley 1998), at least partly due to their differences in power and status in organizations. A woman who has a mentor at a higher level in the organization can be unfairly accused of 'sleeping her way to the top' (Clawson and K ram 1984; Quinn and Lees 1984). There is also distrust about women, a belief that they will use and lie about sex (Berebitsky 2012; Goudreau 2012). This belief has recently been reinforced by Hakim (2011), who has coined the term 'erotic capital' to refer to the combination of beauty, sex appeal, skills of presentation and social skills that make men and women agreeable company and colleagues (2011:1). She argues 'that women should be taught to use their sex appeal to exploit men' (Penny 2011). In one example she talks of 'J ade', who had an affair with her boss. She says that while some might regard J ade's boss's interest in her as sexual harassment, she would 
describe it as 'a mutually rewarding relationship' (2011:46). A s long as the relationship is consensual, she may perceive the relationship as mutually rewarding. However, there are many moral as well as research-supported arguments that would dissuade women from having an affair with their boss. The relationship, like so many, could end in harassment (Pierce et al. 2004). Research has shown that lower-level participants in hierarchical romances are more likely to lose their jobs or be relocated than higher-level participants, especially if they are female (Quinn 1977; Devine and M arkiewicz 1990; Pierce et al. 1996; Riach and W ilson 2008). Q uinn and Lees (1984) reported that women were twice as likely to lose their jobs as the men with whom they were involved. Riach and W ilson (2007) found that employees believed that if a relationship between two people at different levels in the organization broke up, the more junior person should leave; this was usually the female. Women were described as 'over emotional' and 'unstable'. In contrast men were 'coping'. W omen have been found to be more negatively evaluated than men in their motivation for participation in workplace romance (Quinn 1977; A nderson and Hunsaker 1985; A nderson and Fisher 1991; M organ and Davidson 2008). A nderson and Hunsaker (1985) found that while respondents could easily identify the motivation for the female participant, about 15 per cent could not identify it for the male. Women are more likely to be perceived as being involved in a workplace romance to move up the organizational hierarchy, whereas men are perceived as being involved to satisfy their ego needs (A nderson and Fisher 1991). W omen elicit more negative reactions from colleagues than men for being involved in workplace romance (Dillard 1987; Dillard et al. 1994). Negative stereotypes of 'slut', 'tart' and 'slag' are attached to women for being involved in a workplace romance, whereas this is not the case for men 
(Riach and Wilson 2007). W omen, then, are more likely to be at risk of harm from romance at work. W orkplace romances may also be particularly hazardous for same-sex couples due to fellow employees' negative reactions (Powell and Foley 1998). There are good reasons to keep the romance secret.

Romantic secrecy and the reactions of co-workers

Romantic secrecy refers to the deliberate conceal ment of one's ongoing romantic relationship from a person or persons outside of the relationship (Foster et al. 2010) and is omnipresent in workplace romances (Powell and Foley 1998). M ost try to keep the romance a secret but fail (Quinn 1977; Q uinn and Lees 1984; A nderson and Hunsaker 1985). It is claimed that fewer people now keep their workplace romance secret than was the case in 2005: 65 per cent of workers are public with them now (A dams 2011). There are good reasons why the couple try to keep their romance secret. When the romance becomes public knowledge, it provokes reaction (Foley and Powell 1999) and gossip (Quinn 1977; Dillard and M iller 1988). It can stimulate discussion about love, sex, family, power, justice, ethics and norms regarding acceptable behaviour at work (Powell and Foley 1998). Hierarchical romances stimulate more response as they involve issues of power and dependency (M ainiero 1986). The couple may be perceived as forming a coalition that gives them power. As a result, team members may feel that are no longer on an even playing field when one co-worker has formed a coalition with the supervisor. The couple is perceived as a unit and any communication with either partner is assumed to be repeated to the other (J ones 1999). As career rewards (e.g. pay increases, favourable job assignments and promotion) can be exchanged for personal favours in hierarchical 
romances, other organizational members may fear that the relationship is being exploited for personal gain; this then raises issues of equity and justice for co-workers (G reenberg 1987). The issue of fairness and equity is also salient for the participants as if the relationship involves hierarchical difference. There is a risk that employees will lose respect for the higher-level participant, fearing that their judgement about performance is clouded (Spelman and Crary 1984; A nderson and Hunsaker 1985). For the lower-level participant, there may be risks to career, self-image and esteem if they feel uncertain whether their progress in the organization is due to competence or favouritism (Collins 1983; Spelman and Crary 1984).

Reactions from co-workers are intensified if the relationship is extra-marital, and this can lead to a greater deterioration of the work group's social climate (Dillard et al. 1994). Powell (2001) found that respondents perceived a hierarchical romance as representing a more serious problem for the organization when they thought that the lower-level participant was motivated by job concerns. The most negative reactions were reserved for a lower-level female participant being involved with a higher-level male participant. This review will now look in more detail at the impacts of romance in the workplace, both negative and positive.

The negative and positive impacts of workplace romance

Swartz et al. (1987:34) conclude that 'overt sexual behaviour and business do not mix'. Strong sexual attractions interfere with work. Quinn (1977), drawing on a survey asking about romance among co-workers, found that most employees cite negative consequences from workplace romance and say that organizations generally do not take 
effective action. Job productivity can be negatively affected by romance due to long lunches, extended discussions behind closed doors, missed meetings, late arrivals, early departures, and errors (Q uinn and J udge 1978). A review of the literature by Pierce et al. (1996) on the effect of workplace romance on productivity concludes that 'a substantial proportion of the literature indicates that job productivity can be negatively affected by workplace liaisons' (1996: 19), though (Pierce 1998:1726) later reports that 'participating in a workplace romance may not be entirely detrimental to an individual's performance at work' while Pierce and A guinis (2003:161) found romance not to be predictive of ' levels of job performance'. A s B oyd (2010) notes, there is no benchmark evidence in the literature of any attempt to compare productivity gains or losses resulting from romance, so it is impossible to draw firm conclusions on the impact of romance on productivity.

Negative effects also include co-worker disapproval, cynicism, and hostility (A nderson and Fisher 1991), as well as concerns that there will be favouritism and employment benefits given to one party in the relationship by the other (A nderson and Hunsaker 1985). Swartz et al. (1987) found that romantic relationships adversely affect those involved and the co-workers who witness them. Cole (2009) found that no one reported positive effects of workplace romance on the performance of co-workers or work environment. A ny impact was invariably negative. N egative outcomes include conflicts of interest, flawed or biased decision-making and other workplace inequities that have a negative impact on both individual and organizational performance as well as the careers of one or both partners (Powell 1993). 
Research has also shown that employees involved in a workplace romance can be more productive at work (Quinn and Lees 1984; Dillard 1987; Dillard and B roetzmann 1989; Pierce 1998). Levels of productivity may be lower at the start of the relationship as large amounts of time and energy are invested in it. Once the initial excitement of the new romance lessens, productivity tends to rise steadily (Pierce et al. 1996). The motive for the relationship also impacts on productivity. Individuals who participate with a 'love' motive or a sincere desire for companionship tend to show an increase in productivity, while those who participate with an 'ego motive', the desire for excitement, or with a jobrelated motive, the desire for advancement, security or power, tend to show no change in performance (Dillard 1987). Those who show a love motive avoid the negative consequences of inadequate performance by demonstrating increased effort in order to impress their supervisors. J ob satisfaction and organizational commitment also increase (Pierce and A guinis 2003). W orkplace romances that lead to marriage could help individuals to work to their maximum potential as their personal needs are being satisfied; this in turn benefits performance (M ainiero 1989).

There are positive outcomes of organizational romance for others too. For example workplace romance can increase workplace morale and motivate other employees, encourage creativity and innovation. It can create more relaxed and happier work environments (Biggs et al. 2012) and can soften personality conflicts because the workplace romance partners are more content and easier to get along with. It can improve teamwork, communication and cooperation (Cole 2009). However the research also clearly notes the negative impact of romance, in particular its link to harassment. 
Romance and sexual harassment

There has been a good deal of public confusion and controversy over the distinction between sexual behavior and sexual harassment, but court opinions and harassment scholars (e.g. Williams et al. 1999; Schultz 2003) have been careful to maintain one. N ot all sexual behaviour at work is harassing (Berdahl and A quino 2009). There will be employees who enjoy some forms of sexual behaviour some of the time. There are forms of sexual harassment that are clear. However, much is unclear and ambiguous (M arkert 1999). B ehaviour that one individual considers a romantic overture or harmless fun, another might perceive as harassing. Requests for sexual favours in exchange for job security or enhancement are likely to be identified as sexual harassment. However, this clarity becomes 'somewhat murky' (Sias 2008:129) depending on who is involved. If the initiator is male and the target female, the situation is most likely to be perceived as sexual harassment; if the initiator is female, male targets are slightly less likely to interpret it as sexual harassment. The overtness of the behaviour also helps identify the thin line between romance and sexual harassment (M arkert 1999).

W orkplace romance is portrayed in the literature as a major source of sexual harassment (M ainiero 1989; Slovak 1991; Pierce et al. 2008). If a workplace romance breaks down, one partner's attempts at reconciliation may be perceived by the former partner as harassment. Sexual harassment is sex discrimination and the employer can be held responsible for not protecting that employee from such harassment. There is a clear link between failed romance and sexual harassment. Specifically 24 per cent of respondents in one survey indicated that sexual harassment claims had been raised in their organization 
as a direct result of workplace romance (SHRM 1998). R oughly 10 per cent of all women have left a job because of sexual harassment (Gutek et al. 1990). A s we know that nearly 48 per cent of workplace romances dissolve (Henry 1995), it could be argued that we should better understand the conditions under which such terminated relationships result in sexually harassing behaviours at work. Pierce and A guinis (2009) estimated that there will be one harassment case for every 704 romances and proposed that a number of factors play a critical role in influencing the likelihood that terminated romances lead to sexually harassing behaviour. These factors include the type of romance (e.g. how genuine the love motive is), the partner's social power (e.g. if one person in the relationship is a supervisor who can exchange a reward such as a lighter workload for sexual favours), who initiated the dissolution of the romantic relationship, the male partner's sexual proclivity, and the organization's tolerance for sexual harassment. Having a history of romance also impacts on how decision-makers judge a subsequent incident or complaint of sexual harassment (Summers and M yklebust 1992; Pierce et al. 2000; Pierce et al. 2004). (For a review of the literature on sexual harassment see M CD onald 2012.) The law courts too have noted the close association between workplace romance and sexual harassment (Clarke 2006). For example, in the US a court recognized that a workplace romance between a supervisor and a subordinate could generate a hostile environment for the other employees (Bercovici 2007). What does research tell us about how organizations have responded?

What organizations have done to manage romance 
M ost organizations allow romantic relationships, as romance is seen as a 'fact of life' in the workplace (Lickley et al. 2009). Some have banned them (Gautier 2007; B oyd 2010). Organizations such as the $C$ atholic Church ban friendships as well as sexual or romantic relationships in monasteries to avoid adverse affects on the dynamic of the community. Similarly, the military ban fraternization to promote good order and discipline and to avoid the appearance of partiality (Case 2009). The US armed forces have prohibited adultery with military or non-military personnel (Powell and Foley 1998); a similar situation exists in the UK forces (Sylvester 1998). There are clear legal reasons why employers and professional organizations enforce strict guidelines on relationships in the military, between doctors and patients, teachers and pupils, therapists and clients. However, the consensus appears to be that a complete ban is in all organizations is unworkable (Personnel Today 2010). M any organizations that allow romance are silent on the issue of sex in the workplace (Clarke 2006). While they may not wish to have couples engaging in sexual relationships at work, these do occur and may have to be managed. For example, the prison service in B ritain has banned conjugal visits for prisoners because cells are deemed to be public places. However, other countries have taken a different view and more than half of European countries allow them (Casciani 2012).

Given the association between terminated workplace romance and sexual harassment, and the fact that 'numerous' HR managers and consultants believe that workplace romance should be prohibited due to the possibility of harassment claims (Pierce and A guinis 2009), it might be argued that is surprising that organizations do not develop policies for managing workplace romance. In the UK, the most recent survey has found 
that one in seven employers have banned relationships between employees in the same team (Personnel Today 2012b). However, there has been extensive debate in the law journals on how much an employer can constrain matters of romance (Boyd 2010). There are those who argue that organizational policies that try to 'legislate love' (J ones 1999) are violating individual rights (Dillard and B roetzmann 1989). One poll found that 70 per cent of respondents felt that office romances were none of the company's business (Fisher 1994) while a state in the US (N ew Y ork) passed legislation that inhibits companies from having policies prohibiting dating among employees (J ones 1999). As a result, some organizations take no action, while others have intervened to tell the couple of the risks involved in forming romantic relationships, give a verbal reprimand or written warning, or transferred or terminated employees ( $\mathrm{K}$ arl and Sutton 2000; Personnel Today 2012a). Others have introduced informal policies on romance. Riach and Wilson (2007) found that in their research, based in the public house sector, there were informal 'house rules' about romance at work. These informal rules were often simply ignored.

Perhaps due to the fear of violating human rights, relatively few organizations have formal workplace romance policies (A ppel baum et al. 2007). Research from the Society for Human Resource M anagement (SHRM 1998) demonstrated that only 13 per cent of organizations had a workplace romance policy; by 2006 less than a third had policies (Parks 2006). In the UK less than one-third of companies have a policy (Personnel Today 2012b). M ost policies cover only the most blatant instances in which workplace romance may disrupt the conduct of work. The most frequent restrictions are bans on romance between supervisors and subordinates and on public displays of affection (SHRM 1998). 
It could be argued that more organizations need to develop and enforce policies to manage romantic relationships at work, particularly those relationships that are hierarchical and involve a difference in social power (Pierce and A guinis 1997, 2009; Paul and Townsend 1998). It could equally easily be argued that if workplace romance were being managed fairly and consistently, there would be no need for a policy. While professional HR managers may want avoid intervening in workplace romances, employee non-participants in workplace romance say that $\mathrm{HR}$ intervention is needed more frequently than indicated by the HR practitioners themselves (M ichelson et al. 2010). Fair managerial action appears to be the main concern for both co-workers (Riach and W ilson 2007; Cole 2009) and job-seekers (Pierce et al. 2012).

Organizations vary considerably in their response to consensual relationships at work. W al-M art in Germany tried to introduce an ethics policy to ban romantic liaisons at work (Personnel Today 2005). Wal-M art was well known for its anti-fraternization policy in the US before 1994, when they lost a case in court. In 1993 they fired an employee who acknowledged committing adultery (Halverson 1993; A maral 2006; B oyd 2010). WalM art later revised its policy to exclude any reference to married employees but banned dating between supervisors and individuals who report directly to them (Powell and Foley 1998), only to lose its court appeal in Germany when it tried to ban these relationships there (Personnel Today 2005). Other organizations to introduce strict nonfraternization policies include Staples (the office supplies retail chain) and Lloyd's of London (Schaefer and Tudor 2001). 
Consensual dating agreements have been introduced by some employers. These are sometimes referred to as 'love contracts'. They request a couple to sign a document affirming that their workplace romance is consensual, that they will not engage in favouritism, and that they will not take legal action against the employer or each other if the relationship fails. Schaefer and Tudor (2001) and Wilson et al. (2003) provide examples of specimen contracts. However K ramer (2000) questions whether these contracts are possible violations of the privacy rights of employees. The manager may find that an employee will bring a sexual harassment suit anyway (Zachary 2012). Other organizations have introduced codes of conduct. For example, NatW est and Royal B ank of Scotland ask staff to inform the organization if there is any potential for a relationship to cause a conflict of interests; security is cited as a reason (Guest 2005). Wilson et al. (2003) conclude that an employer's legitimate interests in maintaining a peaceful and productive work environment and avoiding liability outweigh an employee's right to privacy. Policies should be reasonable and should not impose on employees' private lives.

Organizations such as Southwest A irlines, A T\&T, X erox (B udak 2012) and Ben and J erry's actively promote romance by recruiting couples. Southwest A irlines boasts 1,200 married couples from its staff of 35,000 (Budak 2012). B en and J erry's human resource manager is quoted as saying 'W e expect that our employees will date, fall in love, and become partners' (A maral 2006:10). 
Having looked at how organizations have responded, we will now turn to and critique the research methods that have been utilized to devel op our knowledge and understanding of workplace romance.

Research methods utilized in workplace romance research

The main research method used to explore workplace romance is surveys. Surveys or polls of workplaces are undertaken by organizations such as B usiness W ire; OfficeClick (Schaefer and Tudor 2001); Career B uilder, who polled 7,780 full time workers in 2011; V ault, who have run office surveys for seven years, recently with a sample of 2083 employees (V ault 2011; A dams 2012); X pertH R, who publish their UK findings in Personnel Today (2012b); and the US Society for Human Resource M anagement (1998, 2002; B ureau of National Affairs 1988; Parks 2006). Early research by Quinn (1977) found that part-time graduate students were hesitant to respond to questions about romantic relationships, so recruited a sample of white-collar employees willing to share their observations on romance. Quinn questioned people waiting at two airports in the B oston area of the US. This and other surveys using convenience samples such as M BA students and soliciting third-party observation (e.g. A nderson and Hunsaker 1985) could have led to actor-observer effects (Pierce et al. 1996). For example, an employee's motive for initiating a romance can be seen differently by the participant in the liaison and by an observer. The individuals may or may not have any personal experience of such relationships. By 1996 Pierce et al. reported that of the 56 studies of workplace romance they reviewed, there had been 14 surveys with between 100 and 1,300 participants mainly conducted by mail or telephone. A Imost all the studies used closed- 
end surveys which also paid little attention to organizational context (Williams et al. 1999). M uch of the research was from case studies (19 drawing on between 1 and 12 cases) or was anecdotal evidence from opportunistic or convenience samples. While these cases and anecdotal material help outline the dynamics of organizational romance, they lack methodological rigour (M ainiero 1986). Recent surveys too have used convenience samples, for example Salvaggio et al.'s (2011b) survey of 197 working adults who had been recruited by undergraduate psychology students as part of an assignment, and their 2010 survey of 113 working adults from local businesses recruited by two graduate students. The strength of the surveys is that they have clearly demonstrated the prevalence of romance. However, methodologically we need to move beyond the surveys towards deeper qualitative research that fully explores the lived experience of romance at work. M uch more research and attention to the topic is required for management and management researchers to better understand the nature, conduct and experience, emphasizing the important connections with power relations both in organizations and across them. But how has the literature to date enhanced our theoretical understanding?

The theoretical contribution of workplace romance research?

B oth the practitioner-oriented and the academic literature on workplace romance is of interest to managers and management scholars, not least because thse bodies of literature offer insight into why individuals enter into workplace relationships and why those affected behave as they do. They also offer a theoretical perspective on personal and professional lives as well as a practical perspective on whether romance impacts on productivity (Gautier 2007) and how employers manage the effect of employees' intimate 
relationships on productivity (Salvaggio et al., 2011b). The first scholarly review of workplace romance was published back in 1977 by Quinn. He defined it and identified factors relevant to the formation of workplace romance, the impact of workplace romance on co-workers and on the wider organization, and subsequent management actions. He presented a model of organizational romance that is theoretically important, as it acknowledges a natural, but at least according to a W eberian model (W eber 1947) deviant, behaviour in organizations. This is because particularistic relationships are deemed inappropriate. The psychologists, drawing on equity and justice theory, note the impact on co-workers' sense of what is fair and equitable (A dams 1965; Cole 2009). As the negative effects of the romantic relationship increase, the coping strategies become more extreme and the negative impact tends to be greater. W hile the couple and those who manage them may want the romance to be a private affair, it is public in that it has an impact on others. This model is of value because it explains why workplace romance may be hurtful to individuals and organizations and why employees may be more aware of the negative impact of romance on the workplace and expect managers to take action.

Since Quinn, M ainiero (1986) has developed a model of how theories of power, dependency and social exchange influence the dynamics of workplace romances and coworker reactions. She also reviewed the antecedent conditions contributing to organizational romances, the decision factors involved, the internal dynamics of relationships, the impact of the romance on the work group and the implications for management intervention. Power is the key variable necessary for understanding the effects and consequences of the romance. The power dynamic is a function of the relative dependency of each partner on the other for resources that are exchanged in the 
relationship. Workplace behaviour will only be affected if the relationship is marked by the exploitative exchange of resources in an unbalanced power relation. Where the power relationship is balanced and both members are equally committed to their organizational and personal roles, work group performance is unlikely to be affected. Pierce et al. (1996) then built on M ainiero's model, producing a detailed and comprehensive model to elaborate on the formation and impact of workplace romances. Portions of this have been tested empirically and there have been several experimental studies on workplace romance (e.g. Pierce et al. 2004). However, before Pierce et al.'s (1996) theory-based model and subsequent tests of this model, papers on workplace romance were largely lacking theory. There are many atheoretical papers that discuss the morality of the phenomenon or document its consequences without a consideration of power differences. As women tend to have less power to provide salient rewards (Ibarra 1993), power is an essential component to consider. A lso, as we have seen in this paper, women, as the less powerful, are the most likely to be hurt by the negative consequences of their participation in romance. M uch of the research is lacking methodological rigour, recruiting convenience samples and those without first-hand experience of romance, either for themselves or others whose romance they have witnessed. Further, it is ironic, given the literature's concern with the impact of romance on productivity, that there has been no attempt to compare productivity gains or losses resulting from romance; so far the results have been 'mixed' (Pierce and A guinis 2009). There needs to be an increase in the level of empirical research to support or disconfirm theories of workplace romance that are al ready available (Powell and Foley 1998) and explore new areas identified here, particularly given how often individuals meet their partners at work. From sociology and 
organizational theorists we learn that while one of the first tasks of bureaucracy is to suppress sexuality (Burrell 1984), managements have contented themselves with the incorporation and close containment of sexual relations in the non-work sphere. However, there has been widespread resistance to such suppression and Burrell (1984) concludes that it seems that resistance is to be found where control over sexual relations would appear most developed. W orkplace romance should not be thought of as good or bad, tolerated or forbidden, but as an expression of sexuality that pervades every aspect of organizations. B anning romance may be shutting down some possibilities that make relationships productive, and the statistics show how many people meet their partners at work. However, this does not mean that we have to accept re-eroticization theory's uncritical acceptance of the full emergence of workplace romance making organizations more passionate, human and exciting places (Burrell 1992; Brewis and Linstead 2000). There are a number of reasons for caution. Firstly it is clear that sexual behaviours at work are more harmful to women. Secondly, power can be abused in workplace relationships and there can be conflicts of interest. Thirdly, greater expression of romance and sexuality may be regarded as less appropriate or acceptable in some settings.

\section{Future directions for research}

The vast majority of the research is based in the US and more research is needed in a variety of countries and cultures in which workplace romance occurs, in order to look more deeply at the influence of culture in organizational romance. Due to the sensitive nature of the topic, it has been assumed that obtaining interviews with those actually involved in romance at work will be problematic, but this is not necessarily the case. As 
most studies are conducted with convenience samples, the samples are unrepresentative in terms of gender (for example 85.6 per cent of Harrison and Lee's sample were male) as well as class and status. W here investigators have used third-party observations of romantic behaviour (Quinn 1977; A nderson and Hunsaker 1985; Harrison and Lee 1986) the individuals questioned may or may not have had first-hand experience of workplace romance. The research on workplace romance has been primarily guided by a positivist perspective relying on self report survey data to gauge preval ence and to test hypotheses. M ore qualitative interview research is needed to glean first-hand experience of workplace romance (Gautier 2007: Williams et al. 1999) and to examine how culture and context impact. Where qualitative interview research has been used, some interesting findings have emerged. For example, Cole's results showed no positive impact of organizational romance on co-workers. Could this be replicated in a different study? What harm would interviewees discuss if not presented with possible answers? If a social constructionist perspective were adopted, would harm or negative impacts be more likely to be construed as the result of romance by co-workers rather than those involved?

We know little about policies, in particular informal policies or 'house rules' that attempt to manage intimate relationships such as the one Riach and W ilson (2007) uncovered. Further research is needed on workers' reactions to workplace policies and their implementation. It is clear that managers in some organizations are still transferring employees involved in romance to ensure that a couple does not work closely together, formally reprimanding or dismissing them (Personnel Today 2012a). The surveys show how pervasive workplace romance policies are, but how consistently are they enforced? W hat is their impact on the behaviour of others? How do employees respond to the 
policies and their punitive consequences? A re the consequences that sexual relationships and activity go 'underground'? W hile it is suspected that much activity of a sexual nature takes place in organizations, sexual relations do not take place uniformly in time and space. W e may learn much from the time-space movements of individuals through an investigation of the location and episodes in the sexual underlife of the organization (Giddens 1981; B urrell 1984). Riach and Wilson (2014) begin to do this in their research, exploring the lived experience of sexuality in one particular organizational setting, in a pub. However, much more research in different locales is needed.

M ore research is also needed to understand gender differences. A re women still being more negatively evaluated than men in their motivation for participation in workplace romance? Research on sex stereotypes shows 'remarkable durability' over time and place (Burgess and B orgida 1999); are sex stereotypes still in evidence, so that women are construed as warm, caring and deferential in relationships at work whereas men are strong and controlling? A re women seen as more romantically competent than men? (Romantic competence - a self-perceived sense of how good one is at dealing with romantic situations - is a relatively new concept that has been studied among adolescents (Bouchey 2007) but not as yet with those working in organizations.) Or do myths endure, such as 'It is women who sleep their way to the top', despite evidence from Gutek (1989) and Swartz et al. (1987:3) that suggests that this myth is 'more a figment of vivid imaginations'? Little research has looked at how sexual intimacy with a superordinate can enhance career status. The exception is Harris and Ogbonna (2006), who found that 4 out of 112 interviewees admitted to enhancing career status through sexual intimacy with a superordinate. 
Tourigny and Dougan (2004) suggest that the literature has typically focussed on a relationship between two people. However, a partner could be experiencing more than one intimate relationship at a time within their network of relationships; future research is needed on this. In addition there is little conceptualization and empirical investigation of infidelity and extra-marital affairs as an organizational phenomenon (for exceptions see J ones 1999 and B rown and Allgeier 1996). The literature has also ignored unrequited love in organizations (B aumiester et al. 1991).

M ore research is needed to better understand how romantic relationships affect others who are not involved in workplace relationships but who are aware of them (B ellas and Gossett 2001). M ore research is required about the context of romance: in particular, how it is viewed among the less well educated and how it unfolds in blue-collar and nonprofessional settings (Riach and Wilson 2007), as to date most of the research has been in white-collar office settings and with executives.

W hat is completely missing from the research to date is an understanding of what the couple themselves think about how they are treated as a couple. For example, given that research has reported negative attitudes from other employees towards married couples in the workplace (W erbel and Hames 1996) and that other employees may see a couple as a power coalition (M ainiero 1986), do the couple feel that people at work treat them as an invincible duo with extra power, rather than as two separate individuals with more limited power? Is power being accrued to the partners in the romantic relationship by the partners themselves and/or by those who witness the romance? Do they use this power to collude to gain objectives they find desirable (for example a role in the organization for a 
relative)? A re they being treated like one and the same person? Do their work colleagues assume that if one feels strongly on a particular work issue, the other will agree? If one of them goes to a meeting, when both are on the invitation list, is that seen as acceptable?

W e also have little understanding of the inconsistency of espoused views on romance and actual behaviour. Research has found that while a manager might advise their staff against having romantic relationships with their subordinates, they may be having relationships themselves (see Wilson and Riach 2008). Further, little is known about the norms of behaviour that are considered acceptable, the rules of engagement (W ilson and Riach 2008), who can do what to whom and the effect of hierarchy, class and gender on this.

Definitions of romance need to include the possibility of same-sex romance and crossorganizational romance. No research appears to have looked at cross-organizational romance, though some employers have rules forbidding dating the employees of competitors, customers or clients (B oyd 2010; P ersonnel Today 2012b). A crossorganizational romances might be with a client, customer, vendor, independent contractor or member of a rival organization. This is another area ripe for research, particularly in situations where there is confidential information at risk or where people are involved in issues of business-related trust such as a relationship between an auditor and a staff member involved in the inspection (Harrison and Lee 1986). W ould those with least power be hurt most when the relationship ended?

\section{Recommendations for managers}


Some commentators have argued that organizations should desexualize the workplace and treat romantic relationships as a kind of 'corporate incest', prohibited behaviour, in order to create a safe space free from sexual demand or threat (M ead 1978; Case 2009). Case (2009) argues that she would like to see the discouragement of sex initiated between those in a direct reporting relationship. One option is to create an organizational climate that discourages romance (Ford and M cL aughlin 1987). M ost commentators, however, agree that expressions of sexuality at work and workplace romance cannot easily be discouraged or prevented. It may need to be managed, particularly if it is hierarchical. Collins (1983) has a number of recommendations for managers as to how to handle romance between two executives at work. $M$ anagers clearly need to limit negative outcomes and exploitative, destructive or non-consensual interpersonal behaviour. The current general advice to employers appears to be to establish a policy or guidelines about workplace romance that is clearly communicated to employees so that all employees understand the potential consequences (Colby 1991; Paul and Townsend 1998; A ppel baum et al. 2007; Pierce and A guinis 2009). Paul and Townsend (1998) lay out two sets of guidelines - one for employers advising them to establish policies and study law, and another for employees. K iser et al. (2006) offer some ideas on how to draft a policy on consensual relationships. The policy needs to be communicated and then applied fairly and consistently. Policies and guidelines should be placed in the company handbook ( $\mathrm{K}$ iser et al. 2006). A $n$ alternative is to make the policy an integral section of an organization's code of ethical conduct (Pierce and A guinis 2009).

Organizations are advised to be cautious of overly strict anti-fraternization polices (A maral 2006). W orkplace romances cannot be banned and should be ignored unless they 
present a serious threat. R omances where a lower-rank employee has a job-related motive and a higher-rank employee has an ego motive (i.e. one participant satisfies personal/sexual needs in exchange for the other participant satisfying task-related and/or career related needs) are thought to present the greatest threat (Powell and Foley 1998; Powell 2001). Even in organizations where there is a positive view of workplace romance, managers may wish to try to manage hierarchical romances. For example, Southwest A irlines employ a policy of moving one person in a couple where there is a supervisor-subordinate relationship (B udak 2012). Y et the interests of both parties have to be protected, so the outcome for both must not be detrimental to themselves or others in the organization. If productivity or job performance drops, if work is disrupted or if there is inappropriate conduct (Clarke 2006), management are advised to intervene. $\mathrm{HR}$ leaders should manage the risks and rewards of workplace romance as part of a performance management system (A guinis 2009; Pierce and A guinis 2009). The employer's interests in maintaining a peaceful and productive work environment and avoiding liability appear to outweigh an employee's right to privacy (W ilson et al. 2003). W hile the law appears to be moving towards protecting employer rights to choose a romantic partner, but not privacy, it still has to offer hard and fast answers to questions that managers face (Gallo 2006), particularly how to minimize the hurt that workplace romance can cause.

\section{References}

A bbott, P. and Tyler, M. (1998). Chocs away: W eight watching in the contemporary airline industry. Sociology, 32, pp. 433-450. 
A dams, J.S. (1965). Inequity in social exchange. In L. Berkowitz, L. (ed.) Advances in Experimental Social Psychology, N ew Y ork: A cademic Press, pp. 276-299.

A dams, S. (2011). How to have a successful office romance. Forbes.com, 31 A ugust, p. 12. http://www.forbes.com/sites/susanadams/2011/08/31/how-to-have-a-successfuloffice-romance/

A dams, S. (2012). The state of the office romance 2012. Forbes.com 10 February, p. 31. http://www.forbes.com/sites/susanadams/2012/02/10/the-state-of-the-office-romance2012/

A guinis, H. (2009). Performance M anagement 2nd edn. U pper Saddle River, NJ : Pearson/Prentice Hall.

A maral, H.P. (2006). W orkplace romance and fraternization policies. Schmidt L abor Research Center Seminar Research Series. http://www.uri.edu/research//rc/research/papers/A maral_Fraternization.pdf

A nderson, C.I. and Hunsaker, P.L. (1985). Why there's romancing at the office and why it's everybody's problem. Personnel, 62, pp. 57-63.

A nderson, C.J . and Fisher, C. (1991). M ale-female relationships in the workplace: Perceived motivations in office romance. Sex Roles 25, pp. 163-180.A ppelbaum, S., M arinescu, A ., K lenin, J. and Bytautas, J. (2007). Fatal attractions: The (mis) management of workplace romance. International J ournal of Business Research, 7, pp. $31-43$. 
B achrach, P. and Baratz, M.S. (1962). Two faces of power. American Political Science Review, 56, pp. 947-52.

B aumeister, R.F., W otman, S.R. and Stillwell, A .M . (1991). U nrequited love: On heartbreak, anger, guilt, scriptlessness and humiliation, J ournal of Personality and Social Psychology, 64, 377-394.

B BC N ews (2012). G mail probe led FBI to CIA chief David Petraeus's affair. 11 November. http://www.bbc.co.uk/news/world-us-canada-20281355

B ellas, M .L. and Gossett, J.L. (2001). Love or the 'lecherous professor': Consensual sexual relationships between professors and students. The Sociological Quarterly, 42, pp. $529-558$.

Bercovici, J. (2007). N otes: The workplace romance and sexual favouritism: Creating a dialogue between social science and the law of sexual harassment. Southern California Interdisciplinary Law J ournal 16, pp. 183-214.

Berdahl, J.L. (2007). The sexual harassment of uppity women. J ournal of Applied Psychology, 92, pp. 425-437.

Berdahl, J.L. and A quino, K. (2009). Sexual behaviour at work: Fun or folly. J ournal of Applied Social Psychology, 94, pp. 34-47.

Berdahl, J.L., M agley, V.J. and W aldo, C.R. (1996). The sexual harassment of men: Exploring the concept with theory and data. Psychology of Women Q uarterly 20, pp. 
527-547.Berebitsky, J. (2012). Sex and the O ffice: A History of Gender, Power and Desire. New Haven, CT: Y ale U niversity Press.

Biggs, D., M athewman, L. and Fulz, C. (2012). Romantic relationships in organizational settings: A ttitudes on workplace romance in the U K and USA. G ender in M anagement: An International J ournal 27, pp. 271-285.

B ouchey, H.A . (2007). Perceived romantic competence, importance of romantic domains and psychosocial adjustment. J ournal of Clinical Child and Adolescent Psychology, 36, pp. 503-514.

B ourgeois, M.J. and Perkins, J. (2003). A test of evolutionary and socio-cultural explanations of reactions to sexual harassment. Sex Roles, 49, pp. 343-351.

Bowring, M .A . and B rewis, J. (2009). Truth and consequences: M anaging lesbian and gay identity in the Canadian workplace. Equal 0 pportunities International 28, pp. 361377.

B oyd, C. (2010). The debate over the prohibition of romance in the workplace. J ournal of Business E thics, 97, pp. 325-338.B rewis, J. (2005). Signing my life away? Researching sex and organization. Organization 12, pp. 493-510.

B rewis, J. and Grey, C. (1994). Re-eroticizing the organization: A n exegesis and critique. Gender, Work and Organization 1, pp. 67-82.

B rewis, J. and Linstead, S. (2000). Sex, work and sex work: Eroticising organization. London: R outledge. 
B rown, T.J . and Allgeier, E.R. (1996). The impact of participant characteristics, perceived motives, and job behaviours on co-workers' evaluations of workplace romances. J ournal of Applied Social Psychology 26, pp. 577-595.

Budak, J. (2012). Love among the cubicles. Canadian Business, 85, pp. 24-28.

B ureau of N ational A ffairs (BNA) (1988). Corporate Affairs: Nepotism, O ffice Romance and Sexual Harassment. Washington, DC: BNA .

Burgess, D. and Borgida, E. (1999). Who women are, who women should be: Descriptive and prescriptive gender stereotyping in sex discrimination. Psychology, Public Policy and Law, 5, pp. 665-692.

Burke, R.J . (2010). Psychologically intimate, romantic and sexually intimate relationships in the workplace. In B urke, R.J . and Cooper, C.L. (eds), Risky Business: Psychological, Physical and Financial Costs of High Risk Behaviour in Organizations. Farnham: Gower Publishing Limited.

Burke, R.J . and M cK een, C.A. (1992). Social-sexual behaviours at work: Experiences of managerial and professional women. Women in Management Review, 7, pp. 22-31.

Burrell, G. (1984). Sex and organizational analysis. Organization Studies, 5, pp. 97-118.

B urrell, G. (1992). The organization of pleasure. In A Ivesson, M . and W illmott, H. (eds), Critical M anagement Studies. London: Sage, pp. 66-88. 
B urrell, G and Hearn, J. (1989). The sexuality of organization. In Hearn, J., Sheppard, D.L., T ancred-Sheriff, P. and Burrell, G. (eds) The Sexuality of Organization. London: Sage.

Byrne, D. and Neuman, J.H. (1992). The implications of attraction research for organizational issues. In K elly, L. (ed.), Issues, Theory and Research in Industrial/O rganizational Psychology. N ew Y ork: Elsevier, pp. 29-70.

Casciani, D. (2012). Sex in prisons to be studied by Howard League. B BC N ews 27 J une. http://www.bbc.co.uk/news/uk-18603360

Case, M .A. (2009). A few words in favor of cultivating an incest taboo in the workplace. Vermont Law Review, 33, pp. 551-558.

Clarke, L. (2006). Sexual relationships and sexual conduct in the workplace. Legal Studies 26, pp. 347-368.

Clawson, J.G. and K ram, K.E. (1984). M anaging cross-gender mentoring. Business Horizons 27, pp. 22-32.

CNN (2007). Red Cross president forced out over personal relationship. 27 N ovember. http://edition.cnn.com/2007/US/11/27/red.cross.resignation/

Cohen, T.F. (1992). M en's families, men's friends: A structural analysis of constraints on men's social ties. In Nardi, P. (ed.), M en's F riendships. Thousand Oaks, CA : Sage.Colby, L. (1991). Regulating love. Personnel, 68, p.23. 
Cole, N. (2009). W orkplace romance: A justice analysis. J ournal of Business Psychology 24, pp. 363-372.

Collins, E.G. (1983). M anagers and lovers. Harvard Business Review, 61, pp. 142-153.

Crail, M. (2006). Rise in workplace liaisons no longer a danger. Personnel Today 25 July, p. 51.

Devine, I. and M arkiewicz, D. (1990). Cross-sex relationships at work and the impact of gender stereotypes. J ournal of Business Ethics, 9, pp. 333-338.

Dillard, J.P. (1987). Close relationships at work: Perceptions of the motives and performance of relational participants. J ournal of Social and Personal Relationships, $\mathbf{4}$, pp. 179-193.

Dillard, J.P. and B roetzmann, S.M . (1989). Romantic relationships at work: Perceived changes in job-related behaviours as a function of participant's motive, partner's motive and gender. J ournal of Applied Social Psychology 19, pp. 93-110.Dillard, J.P. and M iller, K .I. (1988). Intimate relationships in task environments. In Duck, S.W. (ed.), H andbook of Personal Relationships, New Y ork: Wiley, pp. 449-465.

Dillard, J.P. and W itteman, H. (1985). Romantic relationships at work: Organizational and personal influences. Human Communication Research 12, pp. 99-116.

Dillard, J.P., Hale, J.L. and Segrin, C. (1994). Close relationships in task environments: Perceptions of relational types, illicitness and power. M anagement Communication Q uarterly, 7, pp. 227-255. 
Fisher, A .B. (1994). Getting comfortable with couples in the workplace. F ortune, 3 October, pp. 139-144.

Fitzgerald, L.F., W eitzman, L.M ., Gold, Y . and Ormerod, M . (1988). A cademic harassment: Sex and denial in scholarly garb. P sychology of Women Quarterly 12, pp. $329-340$.

Fleming, P. (2007). Sexuality, power and resistance in the workplace. Organization Studies 28, pp. 239-256.

Foley, S. and Powell, G.N. (1999). Not all is fair in love and work: Co-workers' preferences for and responses to managerial interventions regarding workplace romances. J ournal of Organizational Behavior 20, pp. 1043-1056.

Ford, R.C. and M CLaughlin, F.S. (1987). Should Cupid come to the workplace? A n A SPA survey. Personnel Administrator, October, pp. 100-110.

Foster, C.A ., Foster, J .D. and Campbell, W .K . (2010). A re secret relationships hot, then not? Romantic secrecy as a function of relationship duration. The J ournal of Social Psychology 150, pp. 668-688.

Furnham, A . (2012). On your head: D on't be surprised to find cupid among the cubicles. The Sunday Times 12 February. http://www.thesundaytimes.co.uk/sto/public/A ppointments/article870552.ece

Gallo, R.E. (2006). The law on workplace romances. California Lawyer Magazine, February. 
Gallop, J. (1997). F eminist Accused of Sexual Harassment. Durham, NC: Y ale U niversity Press, Public Planet B ooks.

Gautier, C. (2007). M anaging romance in the workplace. J ournal of E mployee Assistance 1st quarter, pp. 7-9.

Gherardi, S. (1994). The gender we think, the gender we do in our everyday organizational lives. Human Relations, 47, pp. 591-610.

Giddens, A . (1981). A Contemporary Critique of Historical Materialism. N ew Y ork: Macmillan.

Giuffre, P.A . and W illiams, C.L. (1994). B oundary lines: Labelling sexual harassment in restaurants. Gender and Society, 8, pp. 378-401.

Glaser, R.D. and Thorpe, J.S. (1986). U nethical intimacy: A survey of sexual contact and advances between psychology educators and female graduate students. American Psychologist, 41, pp. 43-51.

Goudreau, J. (2012). Sex at the office: W hy so little has changed in 150 years.

Forbes.com 22 M ay. http://www.forbes.com/sites/jennagoudreau/2012/05/22/sex-andthe-office-why-little-has-changed-in-150-years/

Greenberg, J.A . (1987). A taxonomy of organizational justice theories. Academy of M anagement Review, 12, pp. 9-22.

Guest, K. (2005). Office affairs. Independent on Sunday 13 M arch. 
Gutek, B .A . (1985). Sex and the Workplace: The Impact of Sexual Behaviour and Harassment on Women, M en and Organizations. San Francisco: J ossey-Bass.

Gutek, B .A . (1989). Sexuality in the workplace: K ey issues in social research and organizational practice. In Hearn, J., Sheppard, D.L., Tancred-Sheriff, P. and Burrell, G. (eds.), The Sexuality of Organization. London: Sage.

Gutek, B .A ., Cohen, A.G . and K onrad, A .M . (1990). Predicting social-sexual behaviour at work: A contact hypothesis. Academy of M anagement J ournal, 33, pp. 560-577.

Hakim, C. (2011). Honey M oney: The Power of E rotic Capital. London: Penguin.

Halverson, H. (1993). Wal-M art cited for dating policy leading to firing of employees. http://findarticles.com/p/articles/mi_m3092/is_n15_v32/ai_14334706/

Harris, L.C. and Ogbonna, E. (2006). A pproaches to career success: A n exploration of surreptitious career-success strategies. Human Resource M anagement, 45, pp. 43-65.

Harrison, R. and Lee, R. (1986). Love at work. Personnel M anagement, January, pp. 2024.

Hearn, J. and Parkin, W. (1987). Sex at Work. B righton: Wheatsheaf B ooks Ltd.

Henry, D. (1995). Wanna date? The office may not be the place. HR focus, 72, 14.

Ibarra, H. (1993). Personal networks of women and minorities in management: A conceptual framework. Academy of M anagement Review 18, pp. 56-87. 
Isadore, C. (2005). B oeing CEO out in sex scandal. CNN M oney, 7 M arch. http://money.cnn.com/2005/03/07/news/fortune500/boeing_ceo/

Illouz, E. (2012). Why love hurts: A sociological explanation. Cambridge: Polity Press. J ones, G.E. (1999). Hierarchical workplace romance: An experimental examination of team member perceptions. J ournal of Organizational B ehavior 20, pp. 1057-1072.

K akabadse, N. and Kakabadse, A . (2004). Intimacy: International survey of the sex lives of people at work. Basingstoke: Palgrave.

Karl, K .A . and Sutton, C.L. (2000). A n examination of the perceived fairness of romance policies. J ournal of Business and Psychology 14, pp. 429-442.

Kiser, S.B., Coley, T., Ford, M . and M oore, E. (2006). Coffee, tea or me? Romance and sexual harassment in the workplace. Southern Business J ournal, 31, p. 35.

K ramer, G.M . (2000). Limited license to fish off the company pier: Towards express employer policies on supervisor-subordinate fraternization. Western N ew England Law J ournal 22, pp. 77-147.

Lickley, N.C., Berry, G.R. and W heelan-B erry, K.S. (2009). Responding to workplace romance: A proactive and pragmatic approach. J ournal of Business Inquiry, 8, pp. 100119. 
Lobel, S.A ., Quinn, R.E., St Clair, L. and W arfield, A . (1994). Love without sex: The impact of psychological intimacy between men and women at work. Organizational Dynamics 23, pp. 4-13.

Lukes, S. (1986). P ower: A Radical View. New Y ork: New Y ork Press.

M ainiero, L. (1986). A review and analysis of power dynamics in organizational romances. Academy of M anagement Review 11, pp. 750-762.

M ainiero, L. (1989). O ffice Romance: Love, Power and Sex in the Workplace. New Y ork: Rawson A ssociates.

M ainiero, L.A . and J ones, K.J . (2013). Sexual harassment versus workplace romance: Social media spillover and textual harassment in the workplace. The Academy of M anagement Perspectives 27, pp. 187-203.

M ano, R. and Gabriel, Y . (2006). W orkplace romances in cold and hot organizational climates: The experience of Israel and Taiwan. Human Relations, 59, pp. 7-35.

M arcuse, H. (1968). O ne-D imensional Man. London: Sphere Books.

M arkert, J. (1999). Sexual harassment and the communication conundrum. Gender Issues 17, pp. 34-52.

M cD onald, J.J. (2000). Failed workplace romances: If you' re lucky you'll just get sued. Employee Relations Law J ournal 2, pp. 101-111. 
M CD onald, P. (2012). W orkplace sexual harassment 30 years on: A review of the literature. International J ournal of Management Reviews 14, pp. 1-17.

M ead, M . (1978). A proposal: We need taboos on sex at work. Redbook, A pril, pp. 3138. Reprinted (1980) in N eugarten, A . and Shafritz, J.M . (eds), Sexuality in Organizations: Romantic and Coercive Behaviours at Work, 3rd edn. Oak Park, IL: M oore Publishing Company.

M ichelson, G., Hurvy, R. and Grunauer, C. (2010). W orkplace romances and HR M : A private matter or organizational concern? International J ournal of Employment Studies 18, pp. 117-149.

M organ, L.M . and Davidson, M .J . (2008). Sexual dynamics in mentoring relationships: A critical review. British J ournal of M anagement 19, pp. S120-S129.

Parks, M . (2006). Workplace Romance: Poll Findings. A lexandria, V A : Society for Human R esource M anagement.

Paul, R.J . and Townsend, J B. (1998). M anaging the workplace romance: Protecting employee and employer rights. Review of Business 19, pp. 25-30.

Peak, M.H. (1995). Cupid in a three piece suit. M anagement Review, 84, p. 5.

Penny, L. (2011). This 'erotic' book is about as seductive as a balance sheet. New Statesman 140, 506812. 
Personnel Today (2005). Court approval for liaisons in the workplace. 22 N ovember. http://www.personnel today.com/articles/2005/11/22/32670/court-approval-for-liaisonsin-the-workplace.html

Personnel Today (2010). Love is in the air: M anaging relationships in the workplace. 12 February. http://www.personneltoday.com/A rticles/12/02/2010/54104/L ove-is-in-the-airmanaging-relationships-in-the-workplace.htm

Personnel Today (2012a) E mployers count the costs of workplace relationships. 28 M arch. http://www. personnel today.com/A rticles/02/04/2012/58432/E mployers-countthe-costs-of-workplace-relationships.htm

Personnel Today (2012b) E mployers frown on workplace relationships, says survey: W orkplace relationships 2012. 14 February. http://www.personnel today.com/A rticles/14/02/2012/58341/E mployers-frown-onworkplace-relationships-says-survey.htm

Pierce, C.A . (1998). Factors associated with participating in a romantic relationship in a work environment. J ournal of Applied Social Psychology 28, pp. 1712-1730.

Pierce, C.A . and A guinis, H. (1997). B ridging the gap between romantic relationships and sexual harassment in organizations. J ournal of O rganizational B ehavior 18, pp. 197200. 
Pierce, C.A . and A guinis, H. (2001). A framework for investigating the link between workplace romance and sexual harassment. G roup and Organization M anagement 26, pp. 206-229.

Pierce, C.A and A guinis, H. (2003). Romantic relationships in organizations: A test of a model of formation and impact factors. M anagement Research 1, pp. 161-169.

Pierce, C.A . and A guinis, H. (2009). M oving beyond a legal-centric approach to managing workplace romances: Organizationally sensible recommendations for $\mathrm{HR}$ leaders. Human Resource M anagement, 48, pp. 447-464.

Pierce, C.A ., Byrne, D. and A guinis, H. (1996). A ttraction in organizations: A model of workplace romance. J ournal of Organizational Behavior 17, pp. 5-32.

Pierce, C.A ., A guinis, H. and A dams, S.K . (2000). Effects of a dissolved workplace romance and rater characteristics on responses to a sexual harassment accusation. Academy of Management J ournal, 43, pp. 869-880.Pierce, C.A., B roberg, B.J ., M cClure, J.R. and A guinis, H. (2004). Responding to sexual harassment complaints: Effects of a dissolved workplace romance on decision-making standards. Organizational Behaviour and Human Decision Processes, 95, pp. 66-82.

Pierce, C.A., M uslin, I.S., Dudley, C.M . and A guinis, H. (2008). From charm to harm: A content-analytic review of sexual harassment court cases involving workplace romance. M anagement Research, 6, pp. 27-45. 
Pierce, C.A., K arl, K . and Brey, E.T. (2012). Role of workplace romance policies and procedures on job pursuit intentions. J ournal of M anagerial Psychology 27, pp. 237-263.

Pinel, E.C., Long, A .E., Landau, M .J ., A lexander, K. and Pyszczynski, T. (2006). Seeing I to I: A pathway to interpersonal connectedness. J ournal of Personality and Social Psychology, 90, pp. 243-257.

Pope, K., Levenson, H. and Schover, L. (1979). Sexual intimacy in psychology training: Results and implications of a national survey. American Psychologist, 34, pp. 682-689.

Powell, G.N. (1993). Women and M en in M anagement 2nd edn. Newbury Park, CA: Sage.

Powell, G.N . (2000). W orkplace romance in the public sector: Sex differences in reactions to the Clinton-Lewinsky affair. P sychological Reports, 87, pp. 1043-1049.

Powell, G.N . (2001). W orkplace romances between senior-level executives and lowerlevel employees: A $n$ issue of work disruption and gender. Human Relations, 54, pp. 1519-1544.

Powell, G.N. and Foley, S. (1998). Something to talk about: Romantic relationships in organizational settings. J ournal of M anagement 24, pp. 421-448.

Powell, G.N . and M ainiero, L.A. (1990). W hat managers need to know about office romances. Leadership and Organizational D evelopment J ournal 11, pp. i-iii. 
Pringle, R. (1989). Bureaucracy, rationality and sexuality: The case of secretaries. In Hearn, J., Sheppard, D.L., T ancred-Sheriff, R. and Burrell, G. (eds) The Sexuality of Organization. London, Sage, pp.158-177.

Quinn, R.E. (1977). Coping with Cupid: The formation, impact and management of romantic relationships in organizations. Administrative Science Q uarterly 22, pp. 30-45.

Quinn, R.E. and J udge, N.A . (1978). The office romance: No bliss for the boss. M anagement Review, July, pp. 43-49.

Quinn, R.E. and Lees, P.L. (1984). A ttraction and harassment: The dynamics of sexual politics in the workplace. Organizational Dynamics 13, pp. 35-46.

Reiss, M . (2008). We don't need a ban in universities. Times Higher 22-28 M ay, pp. 3135.

Riach, K. and W ilson, F. (2007). Don't screw the crew: Exploring the rules of engagement in organizational romance. British J ournal of Management 18, pp. 79-92.

Riach, K. and Wilson, F. (2008). Organizational romance: Theorizing and researching an underexplored phenomenon. In M outinho, L. and Huarng, K.H. (eds), Advances in Doctoral Research in Management, vol. 2. London: W orld Scientific.

Riach, K. and W ilson, F. (2014). B odyspace at the pub: Sexual orientations and organizational space. Organization, pp. 1-17. 
Roy, D. (1974). Sex in the factory: Informal sexual relations between supervisors and work groups. In C.D. Bryant (ed.), D eviant Behaviour, Chicago: Rand M cN ally.

Rumens, N. (2008). W orking at intimacy: Gay men's workplace friendship. Gender, Work and Organization 15, pp. 9-30.

Salvaggio, A .N., Hopper, J. and Packell, K.M . (2011a) Coworker reactions to observing sexual behaviour at work. J ournal of M anagerial Psychology 26, pp. 604-622.

Salvaggio, A.N., Hopper, J.E., Streich, M . and Pierce, C.A . (2011b) Why do fools fall in love (at work)? Factors associated with the incidence of workplace romance. J ournal of Applied Social Psychology, 41, pp. 906-937.

Schaefer, C.M . and Tudor, T.R. (2001). M anaging workplace romances. SAM Advanced M anagement J ournal, 66, pp. 4-10.

Schultz, V. (2003). The sanitized w orkplace. Yale Law J ournal 112, pp. 2061-2193.

Shilling, C. and M ellor, P.A . (2010). Sociology and the problem of eroticism. Sociology, 44, pp. $435-452$.

SHRM (Society for Human Resource M anagement) (1998). Workplace Romance Survey. Item no 62.17014. A lexandria, VA: SHRM Public Affairs Department.

SHRM (2002). Workplace Romance Survey. A lexandria, VA: SHRM Public A ffairs Department. 
SHRM (2011). Every day is V alentine's for some workers. 2 November. http://www.shrm.org/Publications/HR N ews/Pages/V alentinesD ay.aspx

Sias, P. (2008). Romantic workplace relationships. In Sias, P., Organizing Relationships. Thousand Oaks, CA: Sage, pp. 125-154.

Slovak, P.C. (1991). Sex in the workplace: From romance to harassment. The Human Resources Professional, 3, pp. 9-12.

Society for Industrial and Organizational Psychology (2013). Romance in the office is common occurrence. http://www.siop.org/M edia/N ews/office_romance.aspx

Spelman, D. and Crary, M . (1984). Intimacy or distance? A case of male-female attraction at work. Organizational Behavior Teaching Review, 9, pp. 72-85.

Summers, R.J. and M yklebust, K. (1992). The influence of a history of romance on judgements and responses to a complaint of sexual harassment. Sex Roles 27, pp. 345357.

Swartz, R.A., W arfield, A . and W ood, D. (1987). Co-worker romances: Impact on the work group and on career oriented women. Personnel, 64, pp. 22-35.

Sylvester, E. (1998). A rmy's code of conduct relaxes ban on adultery. The D aily Telegraph 20 February, p. 1. 
Tourigny, L. and Dougan, W .L. (2004). M ore than Love and Work: A Critique of Existing Treatments of Organizational Romance. Proceedings of the 2004 A nnual M eeting of the $M$ idwestern A cademy of $M$ anagement, $M$ inneapolis.

US M erit Systems Protection Board (1994). Sexual Harassment in the F ederal Workplace: Trends, Progress, Continuing Challenges. Washington, DC: US government Printing Office.

V ault (2011). Office romance survey results. 7 February. http://blogs.vault.com/blog/workplace-issues/2011-office-romance-survey-results/ W eber, M . (1947). The Theory of Social and E conomic Organization. N ew Y ork: Oxford University Press.

W ellman, B. (1992). M en in networks: Private communities, domestic friendships. In Nardi, P. (ed.), M en's F riendships. Thousand Oaks, CA : Sage, pp. 74- 114.

W erbel, J.D. and Hames, D.S. (1996). A nti-nepotism reconsidered: The case of husband and wife employment. Group and Organization Management 21, pp. 365-379.

W illiams, C.L., Giuffre, P.A . and Dellinger, K . (1999). Sexuality in the workplace: Organizational control, sexual harassment and the pursuit of pleasure. Annual Review of Sociology 25, pp. 73-93.

Wilson, F. and Riach, K. (2008). Organizational romance: Deviancy and discourse, where 'love conquers all' . Paper presented at conference W omen in Science, Radboud University, Nijmegan, $6 \mathrm{M}$ arch. 
Wilson, R.J ., Filosa, C. and Fennel, A . (2003). Romantic relationships at work: Does privacy trump the dating police? D efense Counsel J ournal, 70, pp. 78-88.

W orrall, L. and Cooper, C.L. (2001). W orking patterns and working hours: Their impact on UK managers. Leadership and Organizational J ournal 20, pp. 6-10.

Y elvington, K.A. (1996). Flirting in the factory. J ournal of the Royal Anthropological

Institute 2, pp. 313-333.

Zachary, M .K . (2012). Labor law for supervisors: N on-fraternization policies.

Supervision, 73, pp. 18-22. 